\title{
Numerical Modeling of High-Temperature Corrosion Processes
}

\author{
James A. Nesbitt* \\ Received December 12, 1994; revised January 20, 1995
}

Numerical modeling of the diffusional transport associated with high-temperature corrosion processes is reviewed. These corrosion processes include external scale formation and internal subscale formation during oxidation, coating degradation by oxidation and substrate interdiffusion, carburization, sulfidation and nitridation. The studies that are reviewed cover such complexities as concentration-dependent diffusivities, cross-term effects in ternary alloys, and internal precipitation where several compounds of the same element may form (e.g., carbides of $\mathrm{Cr}$ ) or several compounds exist simultaneously (e.g., carbides containing varying amounts of $\mathrm{Ni}, \mathrm{Cr}, \mathrm{Fe}$ or Mo). In addition, the studies involve a variety of boundary conditions that vary with time and temperature. Finite-difference (F-D) techniques have been applied almost exclusively to model either the solute or corrodant transport in each of these studies. Hence, the paper first reviews the use of F-D techniques to develop solutions to the diffusion equations with various boundary conditions appropriate to hightemperature corrosion processes. The bulk of the paper then reviews various $F$-D modeling studies of diffusional transport associated with high-temperature corrosion.

- KEY WORDS: modeling; numerical modeling; numerical techniques; finite-difference techniques; oxidation; corrosion; carburization; nitridation; diffusion.

\section{INTRODUCTION}

In this paper, numerical modeling will be limited to the methods and techniques describing the diffusional transport within an oxide scale, subscale, or alloy associated with high-temperature corrosion processes. The diffusing

*NASA Lewis Research Center, Cleveland, $\mathrm{OH} 44135$. 
specie(s) may be moving inward as a corrodant. such as occurs during internal oxidation, sulfidation or carburization, or outward as a solute, such as occurs during selective oxidation to form an external protective scale. These diffusional processes are described by the well-known Fick's laws of diffusion, given as

$$
J=-D \frac{\partial C}{\partial X} \quad \text { (First Law) }
$$

and

$$
i C=\frac{\hat{\partial}}{\partial X}\left(D \frac{\partial C}{\partial X}\right) \quad \text { (Second Law) }
$$

where $J$ is the flux and $C$ is the concentration of the diffusing specie, $D$ is the appropriate diffusion coefficient, and $X$ and $t$ refer to distance and time, respectively. In an attempt to maintain clarity, $\mathrm{C}$ and $\mathrm{N}$ will refer to the elements carbon and nitrogen, while $C$ and $N$ will refer to a concentration parameter and to the number of nodes in a grid. respectively. Often, $D$ is assumed independent of concentration $(D \neq f(C))$ such that Eq. (2a) becomes

$$
\frac{\partial C}{\partial t}=D\left(\frac{\partial^{2} C}{\partial X^{2}}\right) \quad \begin{gathered}
(\text { Second Law }) \\
(D \neq(C))
\end{gathered}
$$

When $D$ cannot be assumed independent of concentration. Eq. (2a) can be rewritten as

$$
\frac{\partial C}{\partial t}=D \frac{\partial^{2} C}{\partial X^{2}}+\frac{\partial D}{\partial X} \partial X
$$

and by using the chain rule for $\partial D / \partial X$, Eq. (2a) finally becomes

$$
\frac{\partial C}{\partial t}=D \frac{\partial^{2} C}{\partial X^{2}}+\frac{\partial D}{\partial C}\left(\frac{\partial C}{\partial X}\right)^{2} \quad\left(\begin{array}{c}
\text { Second Law }) \\
(D=f(C))
\end{array}\right.
$$

In most high-temperature corrosion problems, one knows the temperature (even if it is not constant) and desires to describe or predict the extent of the attack at a given time. Typically, a knowledge of the concentration profile ( $C$ vs. $X$ ) for the specie(s) of interest (even if the specie is precipitated as an oxide, carbide, or sulfide), or the thickness of an internal subscale, is sufficient to describe the extent of attack. Throughout this paper, subscale will refer to a zone within an alloy containing a dispersion of one or more precipitates of oxides, carbides, sulfides, etc. Hence, a solution to Fick's 
laws, yielding concentrations and interface positions, is generally sufficient to yield the desired information about the extent of the corrosive attack.

Analytical solutions to Fick's laws are available to describe many situations involving high-temperature corrosion. Examples of these solutions cover such areas as solute oxidation in binary alloys, ${ }^{1}$ internal oxidation, ${ }^{2.3}$ moving boundary problems, ${ }^{4}$ and solute transport during oxidation of ternary alloys. ${ }^{5}$ In addition, generalized solutions have been compiled in standardized texts such as those by Crank ${ }^{6}$ and Jost. ${ }^{7}$ However, each of these solutions requires some form of simplifying assumptions, such as constant diffusion coefficients, isothermal conditions, semi-infinite geometries, or time-independent boundary conditions. Assumptions such as these are often unacceptable for many real-world problems

The utility and usefulness of numerical solutions are their flexibility to accommodate these real-world complexities that occur in many hightemperature corrosion problems. These complexities include strongly concentration-dependent diffusion coefficients (e.g., $D$ in $\beta$ NiAl), timevarying boundary conditions (e.g., the discontinuous rate of solute consumption due to oxide spallation during cyclic oxidation), complex initial conditions (e.g., a near-surface solute enrichment due to a coating treatment or a solute depletion due to a preoxidation exposure), finite specimen geometries, precipitation of multiple compounds of one or more solute elements (e.g., carbide formation), and nonisothermal conditions affecting the diffusion coefficients, boundary conditions or solubility products.

Various numerical techniques have been employed to solve the differential equations associated with diffusional transport, however, the most common technique has been that of finite differences (F-D). To the author's knowledge, the F-D technique is the only numerical method which has been applied to modeling transport associated with high-temperature corrosion, although other techniques ${ }^{8}$ could certainly be applied. Hence, only the F-D technique will be discussed in this paper. In the following sections, this technique will be described followed by various examples in the literature of how F-D techniques have been used in the area of high-temperature corrosion modelling.

\section{BASICS OF THE F-D TECHNIQUE}

The initial step in the F-D technique is to establish a grid across a region of the material over which diffusion will occur. The grid consists of $N$ nodes with a spacing between nodes of $\Delta X$. Typically, the node spacing is uniform although a finer or coarser, grid spacing can be used in regions where the concentration gradient is anticipated to be either steep, or shallow, respectively. Each node of the grid has a specific concentration associated 
with it. Fick's laws (Eqs. (1) and (2)) are replaced with F-D equivalents based on small differences in concentration, $\Delta C$, distance, $\Delta X$, and time, $\Delta t$, as shown in the following section. A solution yielding the concentration profile at some time $t$ is derived by solving the appropriate F-D equivalents for small time increments $(\Delta t)$ in an iterative manner. These iterations, or time steps, are continued until the $\Delta t$ increments sum to the desired time $t$. Because of the typically large number of repetitive and tedious calculations made each iteration, F-D solutions are ideally handled by a computer.

\section{Explicit and Implicit F-D Methods}

The F-D equivalents to Fick's laws are based on Taylor series expansions. "The first order, central-difference equation to Fick's first law (Eq. (1)) is given as

$$
J_{n}^{i}=-D\left(\frac{C_{n+1}^{i}-C_{n-1}^{i}}{2 \Delta X}\right) \quad(n=2 \text { to } N-1)
$$

where the subscript refers to the node number and the superscript $i$ refers to the time increment or iteration. In this section dealing with the F-D technique, the subscript to $C(1,2,3, \ldots, N)$ will refer to the node number, whereas in the following application section of the paper, the subscript to $C(\mathrm{O}, \mathrm{C}, \mathrm{N}$, etc.) will refer to a corrodant or solute. The F-D equivalent of Fick's second law can be given by either an explicit or implicit representation. The explicit form for the case where $D \neq f(C))$ is given as

$$
C_{n}^{i+1}-C_{n}^{i} \simeq_{2}^{1} D\left(\begin{array}{c}
C_{n+1}^{i}-2 C_{n}^{i}+C_{n \cdot 1}^{i} \\
\Delta t \\
(\Delta X)^{2}
\end{array}\right)
$$

Explicit Representation $(n=2$ to $N-1)$

where the superscript $i$ refers to the current iteration at time $t$ and the superscript $i+1$ refers to the next iteration at time $t+\Delta t$. It can be seen that with the explicit representation, $C_{n}^{i+1}$ can be calculated directly, or explicitly, from the known concentrations at time $i, C_{n}^{i}$. A portion of a concentration grid at time $t$ and the new concentrations at $t+\Delta t$, are shown schematically in Fig. 1. Forward and backward difference equations, such as for calculating the flux at a boundary (i.e., at $n=1$ or $n=N$ ), and higher order difference equations containing more terms than those shown in Eqs. (3) and (4) (e.g., $C_{n-2}$ and $\left.C_{n+2}\right)$, are available. ${ }^{9.10}$ However, higher-order difference equations have seldom been used in modeling diffusional transport associated with high-temperature corrosion. The time increment for the explicit method is 


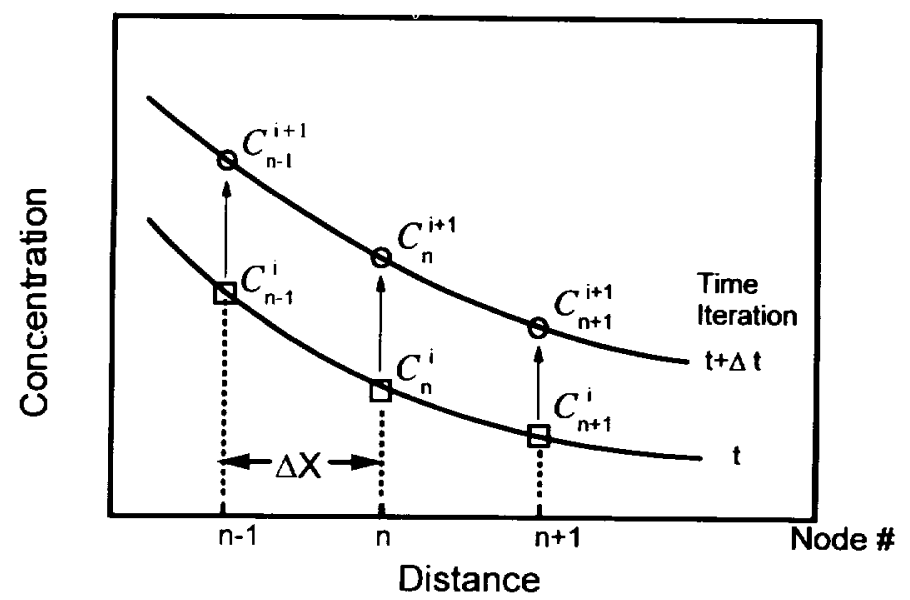

Fig. 1. Schematic concentration grid for time $t$ (squares) and time $t+\Delta t$ (circles). The concentration subseript refers to the node number and the superscript refers to the time iteration.

limited by a stability criterion" given as

$$
D \frac{\Delta t}{(\Delta X)^{2}} \leq 0.25 \quad \text { Stability Criterion for Explicit Method }
$$

The most common implicit F-D method incorporates the CrankNicholson (C-N) representation. For the case where $D \neq f(C)$, Eq. (2b) becomes

$$
\frac{C_{n}^{i+1}-C_{n}^{i}}{\Delta t}=\frac{1}{2} D\left\{\frac{\left(C_{n+1}^{i+1}-2 C_{n}^{i+1}+C_{n-1}^{i+1}\right)}{\Delta X^{2}}+\frac{\left(C_{n+1}^{i}-2 C_{n}^{i}+C_{n-1}^{i}\right)}{\Delta X^{2}}\right\}
$$

Implicit C-N Representation $(n=2$ to $N)$

It can be seen that with the implicit representation, calculating $C_{n}^{i+1}$ requires not only the known concentration values at time $i$, but also the unknown values $C_{n-1}^{i+1}$ and $C_{n+1}^{i+1}$. However, it can be shown ${ }^{9}$ that when Eq. (6) is used, a very desirable tridiagonal matrix of unknowns can be formed which can be solved using standard matrix algorithms to determine the values for the $\mathrm{C}_{n}^{i+1}$. The C-N implicit method is very stable and does not suffer from the restriction on the size of $\Delta t$ as does the explicit method. Larger time increments are desirable since they result in less iterations, less computation time and less possibility of roundoff or truncation error.

When diffusion coefficients are strongly concentration dependent, each of the differential terms in Eq. (2c) are replaced by F-D equivalents and an 
explicit method of solution must be used subject to the stability criterion for $\Delta t$ given in Eq. (5). An explicit method may also be desirable when a strongly time-dependent boundary condition requires the use of small time increments negating some of the benefit of the greater $\Delta t$ of the implicit method. In addition, the explicit method is also attractive by generally being more straightforward to program and routinely yields satisfactory results when computer time, or the likelihood of significant roundoff error, is not a concern. Otherwise, whenever the concentration dependence of the diffusivities is unknown or can be ignored, the implicit F-D method is to be preferred since it is inherently more stable and thus a more efficient solution allowing the use of larger values of $\Delta t$.

\section{Initial and Boundary Conditions}

A specific solution to Fick's second law, whether by explicit or implicit methods, requires initial and boundary conditions. Concentration values are initially assigned to each of the nodes in the grid to reflect the starting concentration condition within the sample or component. This initial condition may be as simple as a uniform concentration throughout a sample (e.g., $C_{n}=C^{\prime \prime}$ for $n=1$ to $N$. where $C^{\prime \prime}$ is the bulk concentration of the component), or a complicated profile, such as a near-surface solute enrichment due to the presence of a coating ${ }^{11.12}$ or a near-surface solute depletion resulting from an intentional, or unintentional, preoxidation exposure. ${ }^{13.14}$

Boundary conditions are required to calculate the new boundary concentrations, $C_{1}^{i+1}$ and $C_{N}^{i+1}$. These boundary conditions are generally defined by either a fixed concentration or a flux condition. A constant solute concentration at the oxide metal interface during isothermal oxidation (e.g., $C_{1}=$ $C^{\prime \prime}$ ) is an example of a fixed concentration boundary condition at an outer surface. A constant solute concentration at the innermost node which never changes due to the thickness of the sample or component (e,g., $C_{N}=C^{\prime}$ ) is an example of the same type of boundary condition applied at an inner boundary. This latter boundary condition is appropriate for samples which can be considered "infinitely thick" in comparison to the diffusion distances during the time span of the corrosive attack. ${ }^{15}$ In contrast, diffusion often reaches to the center of a sample or component. In this case (i.e., finite sample thickness), a zero-flux plane is commonly used as an inner flux boundary condition. ${ }^{16}$ A zero-flux plane indicates that solute is being removed from, or corrodant is being supplied to the center of the sample in both directions equally. Similarly, a flux of $\mathrm{N}$ or $\mathrm{C}$ into an alloy controlled by the dissociation of ammonia or methane on the surface is an example of a flux boundary condition at an outer surface. ${ }^{17.1 \%}$ 


\section{Moving Boundaries, Fixed- and Flexible-Grid Schemes}

Many problems associated with high-temperature corrosion processes involve moving boundaries. Examples of such moving boundaries include recession or growth of an oxide metal interface, growth of a subscale layer, and growth of a different, near-surface phase in the alloy. These moving boundaries have been handled in different ways by F-D studies. In many problems, a flexible-grid scheme is used in which the total grid expands or contracts to match the interface motion. When the grid expands or contracts, the concentrations at the nodes must be adjusted. The most common method of shifting the node positions and adjusting the node concentrations is that referred to as a "Murray-Landis" (M-L) transformation." This transformation shifts the nodes an amount proportional to their position from the moving boundary to maintain a uniform node spacing. Although the $\mathrm{M}-\mathrm{L}$ transformation has been used extensively in the past, Crusius et al. ${ }^{20}$ suggest an extensive modification which yields a higher accuracy under a wider range of conditions. However, this modification results in a considerable increase in the computation time. Moving boundaries using a flexible-grid scheme and an M-L transformation can be treated by either implicit or explicit F$D$ methods. Several examples in the applications section of this paper have employed the M-L transformation. ${ }^{11,12.15 .16}$ In contrast, one study has also shown the feasibility of modeling interface motion with a fixed-grid scheme. ${ }^{21}$

Lastly, the formation and growth of carbide subscale layers has been handled in a different fashion by considering the carbide formation at each individual node. Two methods have been used, both with fixed grid schemes. These methods are discussed in greater detail in the application section dealing with carbide formation.

\section{APPLICATIONS OF THE F-D TECHNIQUE}

The following sections are intended to briefly review several applications of the F-D technique in the area of high-temperature corrosion with the intent to give the reader a sense of the applicability and flexibility of the technique. Two general cases will be examined, firstly, corrosion processes that involve solute transport outward, such as occurs in the selective oxidation of $\mathrm{Al}$ - or $\mathrm{Cr}$-containing alloys and coatings, and secondly, corrodant diffusion inward, such as occurs during nitridation, internal oxidation and carburization.

\section{Case I. Solute Transport}

\section{Protective External Scale Formation}

Whittle et $a .^{22}$ presented one of the earliest known studies utilizing the F-D technique to predict solute transport in binary alloys. Their model 
examined the effect of parabolic, cubic and logarithmic oxide growth rates on the solute concentration and time dependence of the solute concentration at the alloy surface, $C_{\mathrm{B}}^{\mathrm{s}}$. Hence, the flux boundary condition in terms of the solute B can be stated as

$$
\left.J_{\mathrm{B}}\right|_{X=0}=-\left.D \frac{\partial C_{\mathrm{B}}}{\partial X}\right|_{X=0}=\eta\left(k_{\mathrm{I}} t+k_{\mathrm{II}}\right)^{-\phi}
$$

where $J_{\mathrm{B}}$ is the solute flux in the alloy at the oxide-metal interface, $k_{\mathrm{I}}$ and $k_{\mathrm{II}}$ are oxidation rate constants, $\eta$ is a constant dependent on the oxide stoichiometry, the units for the solute flux and oxide growth rates, etc., and $\phi$ has the value $\frac{1}{2}$ for a parabolic rate, $\frac{2}{3}$ for a cubic rate, and 1 for a logarithmic rate. The model quantified the time dependence of the solute concentration at the alloy surface and predicted concentration-distance profiles within the alloy for the three oxide growth rates. In applying the model to the isothermal oxidation of various $\mathrm{Fe}-\mathrm{Cr}$ alloys, reasonable agreement was observed between measured and predicted $\mathrm{Cr}$ concentrations at the oxide-metal interface and concentration-distance profiles within the alloys at different times. ${ }^{23}$ This analysis was then applied to show that the breakdown in protective $\mathrm{Cr}_{2} \mathrm{O}_{3}$ scale formation on $\mathrm{Fe}-(13-25 \mathrm{wt} . \%) \mathrm{Cr}$ alloys cannot be attributed to a chemical transformation within the alloy due to a general depletion of $\mathrm{Cr}$ since the $\mathrm{Cr}$ concentration is never reduced below that necessary for thermodynamic stability of the $\mathrm{Cr}_{2} \mathrm{O}_{3}$ scale.

Nesbitt $e t$ al. also used F-D techniques to predict Al concentrations in $\beta \mathrm{NiAl}$ alloys, ${ }^{16}$ and $\mathrm{Al}$ and $\mathrm{Cr}$ concentration profiles in $\gamma \mathrm{NiCrAl}$ alloys ${ }^{15}$ undergoing cyclic oxidation. During thermal cycling, the oxide which grows at high temperature undergoes partial spalling on cooling. The practical consequence of this oxide spalling is to increase the rate of solute consumption over that for the isothermal case. An oxide spalling model, COSP, ${ }^{24}$ which predicted this accelerated loss of $\mathrm{Al}$, was used as a flux boundary condition at the oxide metal interface for both the $\mathrm{NiAl}$ and $\mathrm{NiCrAl}$ studies. In addition, both studies used an explicit F-D method to take into account the concentration dependence of the diffusivities (see Eq. (2c)). Recession of the alloy surface due to the loss of $\mathrm{Al}$ during selective oxidation was also taken into account. This oxide-metal interface recession, $\Delta \xi$, is defined as ${ }^{15}$

$$
\Delta \xi=-V_{\mathrm{Al}} J_{\mathrm{Al}}^{\mathrm{ox}} \Delta t
$$

where $V_{\mathrm{A} I}$ is the partial molar volume of $\mathrm{Al}$ in the alloy and $J_{\mathrm{Al}}^{\mathrm{ox}}$ is the flux of $\mathrm{Al}$ entering the oxide (which is greater than the flux of $\mathrm{Al}$ in the alloy at the oxide metal interface because of the interface motion). An M-L transformation was used to adjust the concentration grid for this alloy surface recession. 
In the NiAl modeling study ${ }^{16}$ the $\mathrm{F}-\mathrm{D}$ model predicted $\mathrm{Al}$ concentration profiles within thin coupon samples after various cyclic oxidation exposures. A zero-flux boundary condition was used at the center of the sample where the $\mathrm{Al}$ concentration was shown to decrease due to the limited finite sample thickness. The modeling showed that the Al concentration throughout the entire sample (up to $2 \mathrm{~mm}$ thickness) decreased somewhat uniformly as Al was removed from the sample by oxidation. These predictions were verified by concentration measurements on oxidized samples. This relatively uniform decrease in $\mathrm{Al}$ was due to the rapid $\mathrm{Al}$ transport in the alloy in comparison to the rate that $\mathrm{Al}$ was consumed by oxidation. The practical consequences of this observation are (1) oxidation cannot be viewed as only affecting a near-surface region, and (2), the mechanical properties of $\beta \mathrm{NiAl}$ alloys which are concentration dependent can be significantly affected by the uniform loss of $\mathrm{Al}$ during oxidation. Cyclic oxidation testing of $\mathrm{NiAl}$ alloys ${ }^{16}$ showed that the protective $\mathrm{Al}_{2} \mathrm{O}_{3}$ scale was slowly replaced by a lessprotective $\mathrm{NiAl}_{2} \mathrm{O}_{4}$ scale when the $\mathrm{Al}$ concentration in the alloy decreased below approximately 36 at. $\%$. This value was then taken as a failure criterion and the protective lifetimes of various $\beta \mathrm{NiAl}$ alloys of different thickness were predicted. Reasonable agreement was shown between predicted and observed protective lifetimes.

In $\mathrm{NiCrAl}$ alloys, ${ }^{15}$ both $\mathrm{Al}$ and $\mathrm{Cr}$ concentration profiles were predicted for the case of cyclic oxidation. For NiCrAl alloys, Fick's laws can be written as

$$
J_{j}=-D_{j, j} \frac{\partial C_{j}}{\partial X}-D_{j, k} \frac{\partial C_{k}}{\partial X} \quad j, k=\mathrm{Al}, \mathrm{Cr} \quad \text { First Law }
$$

and

$$
\partial C_{j}=\frac{\partial\left(D_{j, j}\left(\partial C_{j} / \partial X\right)\right)}{\partial X}+\frac{\partial\left(D_{j, k}\left(\partial C_{k} / \partial X\right)\right)}{\partial X} \quad j, k=\mathrm{Al}, \mathrm{Cr}
$$

Second Law

where the main diffusivity, $D_{j, j}$, relates the concentration gradient of component $j$ to the flux of $j$ and the off-diagonal, or cross-term diffusivity, $D_{j, k}$, relates the concentration gradient of component $k$ to the flux of $j$. Equation (10) was expanded as for the binary case (Eq. (2c)) and each of the terms was replaced with a F-D equivalent for solution by the explicit method. The oxide-metal interface recession due to Al loss was calculated as shown above for the NiAl alloys (Eq. (8)). However, since $\mathrm{Cr}$ is $\mathrm{n}$ t consumed in the oxide scale, $\mathrm{Cr}$ must diffuse away from the receding oxide-metal interface 
$(X=\xi)$. The outer boundary condition for $\mathrm{Cr}$ then becomes

$$
\left.J_{C \mathrm{r}}\right|_{X-\xi}=C_{\mathrm{Cr}} d \xi
$$

where $J_{C r}$ is the flux of $\mathrm{Cr}$ in the alloy at the interface and $C_{C r}^{5}$ is the $\mathrm{Cr}$ concentration at this interface.

The F-D model ${ }^{15}$ predicted the rate at which the Al concentration at the oxide metal interface decreased with time due to the higher rate of $\mathrm{Al}$ consumption associated with cyclic oxidation. The model was also used to predict the minimum $\mathrm{Al}$ necessary to maintain a protective $\mathrm{Al}_{2} \mathrm{O}_{3}$ scale during cyclic oxidation. It is well known that the addition of $\mathrm{Cr}$ to $\mathrm{NiAl}$ alloys greatly reduces the amount of $\mathrm{Al}$ necessary for protective scale formation during cyclic oxidation. Good agreement was observed between predicted and experimental data for alloys with $\mathrm{Cr}$ concentrations greater than 20 at. $\% \mathrm{Cr}$. However, the model significantly underpredicted the amount of $\mathrm{Al}$ for binary $\mathrm{Ni} \mathrm{Al}$ alloys by a factor of 2.5 . The modeling results showed that the beneficial effect of $\mathrm{Cr}$ additions to $\mathrm{Ni} \mathrm{Al}$ alloys could not be attributed to any transport-related effect of $\mathrm{Cr}$ enhancing the $\mathrm{Al}$ transport to the oxide scale. The implication of this result is that the addition of Cr likely acts as a sacrificial element reducing the transient formation of $\mathrm{Ni}$ oxides when the bare metal is exposed, either at the start of oxidation, or after oxide spallation.

\section{Overlay Coating Degradation}

Degradation of $\gamma+\beta \mathrm{MCrAl}(\mathrm{M}=\mathrm{Ni}$ or $\mathrm{Co})$ overlay coatings on $\mathrm{Ni}$ and Co-based substrates during isothermal and cyclic oxidation has also been modeled in two studies. ${ }^{11.12}$ Overlay coatings are deposited on superalloys to provide an $\mathrm{Al}$ reservoir and extend the protection afforded by the protective $\mathrm{Al}_{2} \mathrm{O}_{3}$ scale. During high-temperature exposure in an oxidizing environment, this reservoir of $\mathrm{Al}$ in the coating is reduced both by consumption of $\mathrm{Al}$ by selective oxidation and by interdiffusion of $\mathrm{Al}$ into the substrate. Therefore, Al diffusion to the oxide and into the substrate was modeled. The two models used different failure criteria to quantify the protective life of the coating. This selection of the failure criterion affected how diffusion within the $\gamma+\beta$ coating was modeled.

In the earlier model by Nesbitt and Heckel " the protective coating . lifetime was defined as the time at which the $\mathrm{Al}$ concentration at the oxide coating interface decreased to zero. Experimental studies showed that the $\beta$ phase within the coating was totally depleted long before the Al concentration at the oxide metal interface approached zero. Consequently, it was assumed that the two-phase structure of the coating could be represented 


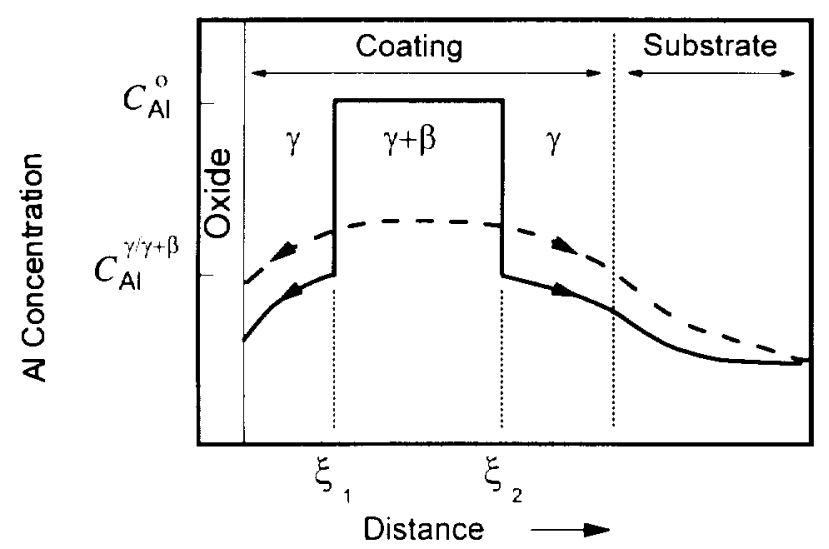

Fig. 2. Schematic Al concentration profile after oxidation of a $\gamma+\beta$ MCrAlY overlay coating on a superalloy substrate. The dashed line represents predictions from the model by Nesbitt "t al." and the solid line represents predictions for the model by Lee at $a l^{12}$ Arrows indicate the direction of Al diffusion from the $\gamma+\beta$ region of the coating

as a single $\gamma$-phase layer with the initial condition given as the initial $\mathrm{Al}$ and $\mathrm{Cr}$ concentrations of the coating $\left(\mathrm{C}_{\mathrm{Al}}, \mathrm{C}_{\mathrm{Cr}_{\mathrm{r}}}\right)$. The $\mathrm{Al}$ concentration profile in the coating and substrate showing the effect of this assumption is shown schematically in Fig. 2. Since diffusion of $\mathrm{Al}$ to the oxide scale and into the substrate is largely controlled by diffusion in the $\gamma$ phase, concentrationdependent, ternary diffusivities appropriate for the $\gamma$ phase were used. Cyclic oxidation conditions were modeled by taking the rate of $\mathrm{Al}$ consumption predicted by the COSP oxide spalling model ${ }^{24}$ as a flux boundary condition at the oxide coating interface. Surface recession due to loss of $\mathrm{Al}$ to the oxide scale was also taken into account. Good agreement between measured and predicted concentration profiles was observed after both cyclic furnace testing of $\mathrm{NiCrAlZr}$ coatings on simple $\mathrm{NiCrAl}$ substrates and cyclic burner rig testing of $\mathrm{NiCoCrAlY}$ coatings on a Ni-base superalloy (Fig. 3). ${ }^{25}$ Based on this satisfactory verification of the model's predictive capability, the effect of various system parameters (c.g., the initial $\mathrm{Al}$ and $\mathrm{Cr}$ content in the coating and substrate) on the protective life of the coating was examined. A further practical consequence of this study was the demonstration that more Al can diffuse into low Al-containing substrates than is lost to the oxidation process.

In the later model developed by Lee $e t a l . .^{12}$ the protective coating lifetime was defined as the time at which the $\beta$ phase was totally depleted from the coating. The practical application of this failure criterion might 


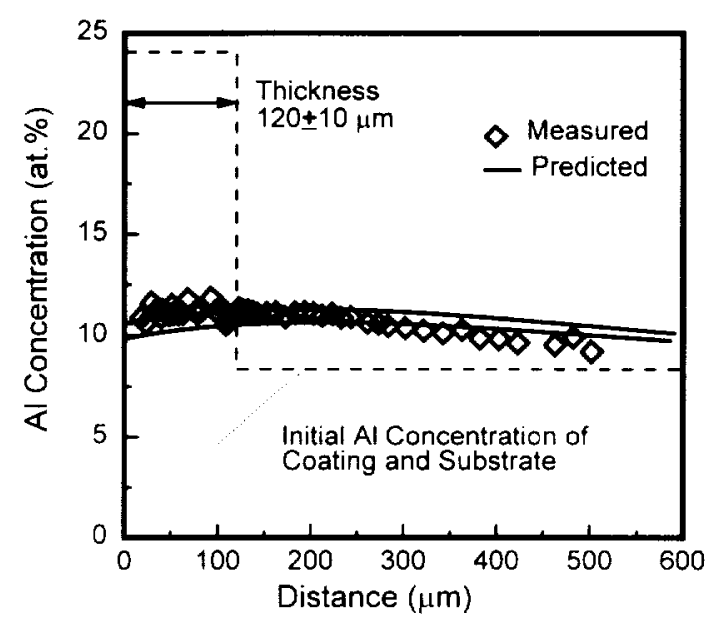

Fig. 3. Measured and predicted Al concentration profiles for a NiCoCrAlY coating on U-700 superalloy after 1000 $1-\mathrm{h}$ cycles in a furnace at $1100 \mathrm{C}^{25}$

signal the time at which a coated component be removed from service and the coating stripped and a new coating applied. Recession of the $\beta$ phase due to $\mathrm{Al}$ diffusion from the coating to the oxide scale and into the substrate was accomplished by establishing moving boundaries on both sides of the coating (Fig. 2). A flexible-grid scheme was used and an M-L transformation was employed to shift the node positions and concentrations after the interface motion. The boundary condition at the $\gamma / \gamma+\beta$ interface is given by

$$
\left(C_{\mathrm{Al}}^{\prime}-C_{\mathrm{Al}}^{\gamma, \gamma}\right) d \xi / d t=\left.J_{\mathrm{Al}}^{\gamma / \beta}\right|_{X-\zeta}
$$

where $J_{\mathrm{Al}}^{\gamma}{ }^{\gamma+\beta}$ is the flux in the $\gamma$ phase at the $\gamma / \gamma+\beta$ interface located at $X=\xi, C_{\mathrm{Al}}^{\circ}$ is the initial Al concentration in the coating, and $C_{\mathrm{Al}}^{\gamma / \gamma+\beta}$ is the maximum $\mathrm{Al}$ concentration in the $\gamma$ phase given by the endpoint of a tie line passing through $C_{\wedge 1}$ in the $\gamma+\beta$ region of the phase diagram. No diffusion was allowed in the $\gamma+\beta$ region of the coating and the value of $C_{\mathrm{Al}}^{\gamma / \gamma}$ on each side of the coating was assumed constant. The Al concentration dependence of $D_{\mathrm{AIAl}}$ was taken into account although the effect of $\mathrm{Cr}$ on the diffusion of $\mathrm{Al}$ in the $\gamma$ layer was ignored (i.e., only $\mathrm{Al}$ transport was modeled). A rate of $\mathrm{Al}$ consumption appropriate for either isothermal or cyclic oxidation was used as a flux boundary condition at the oxide-coating interface. ${ }^{24}$ Good agreement was observed between the measured and predicted volume fraction of $\beta$ remaining in the $\gamma+\beta$ region of the coating following isothermal oxidation of a CoCrAlY coating on a Co-base superalloy (Fig. 4). This model was also used to evaluate the effect of various 


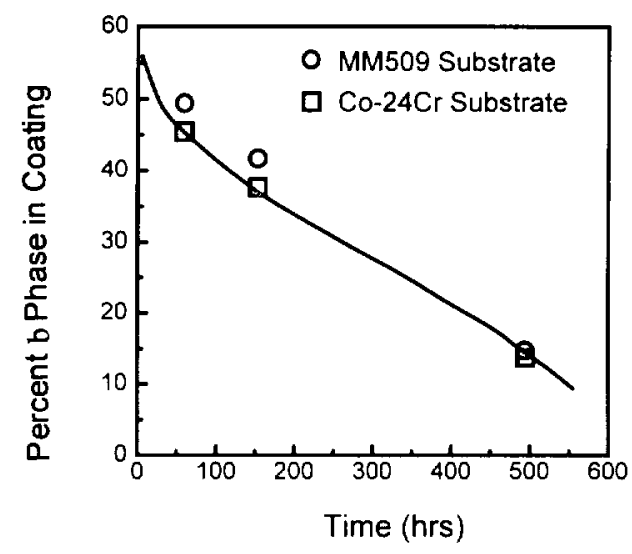

Fig. 4. Measured and predicted volume fraction of $\beta$ phase in the $\gamma+\beta$ Co $17 \mathrm{Cr} 23 \mathrm{Al} 0.3 \mathrm{Y}$ (at.\%) coating on two superalloy substrates after isothermal oxidation.'?

parameters (coating thickness, oxide growth rate, isothermal vs. cyclic oxidation conditions, etc.) on the protective life of the coating for the failure criterion stated above. It is noteworthy that both models simulating overlay coating degradation were used to perform parametric analyses to examine the impact of various parameters on the coating life. This use of these models emphasizes an important aspect of modeling studies, namely, to use the model to identify the most important parameters having the greatest impact in a problem, especially in complex problems such as multiphase coatings on superalloy substrates.

\section{Case II.A Corrodant Transport in the Absence of Internal Precipitation}

Carburization, or nitridation, of $\mathrm{Fe}$ - and $\mathrm{Ni}$-based alloys may be intentional, such as to provide some near-surface mechanical properties in a component, or unintentional, such as occurs upon exposure of components during high-temperature operation in a $\mathrm{C}$ - or $\mathrm{N}$-containing environment (i.e., a high-temperature corrosion process). Modeling the carburization or nitridation process, whether it occurs intentionally or as the result of corrosion, is accomplished in an identical manner. Hence, several examples below involve the intentional nitridation and carburization of Fe-based alloys and are discussed to demonstrate the flexibility of the F-D technique.

\section{Nitridation}

Nitriding $\alpha$ (bcc) Fe-base alloys is a common practice to improve the tribological properties of the surface by the formation of a near-surface, 
nitride-containing layer and an inner region containing $\mathrm{N}$ dissolved interstitially. Analytical solutions to this diffusion problem exist if the surface concentration, $C_{\Lambda}^{\mathrm{s}}$, is assumed to be constant. However, Rozendaal et $\mathrm{al}^{17}$ presented experimental evidence that $C_{N}^{*}$ only slowly approaches the equilibrium concentration during nitridation. Hence, these authors used F-D techniques to model the diffusion of $\mathrm{N}$ into thin sheets of $a-\mathrm{Fe}$. The time to reach a critical surface concentration where $\gamma^{\prime} \mathrm{Fe}_{4} \mathrm{~N}$ would form was predicted, but the precipitation and growth of this nitride subscale layer was not modeled. The nitriding process based on the dissociation of ammonia, can be broken into two steps (assuming no lack of ammonia transport to the surface): (1) the dissociation of ammonia at the Fe surface, and (2) diffusion of $N$ into the sample. The dissociation process is reaction-rate controlled and can be described as

$$
J_{N}=k\left(C_{N}^{\mathrm{ec}}-\left({ }_{N}\right)\right.
$$

where $J_{N}$ is the flux of $\mathrm{N}, k$ is the reaction rate coefficient. $C_{N}$ is the $\mathrm{N}$ concentration in $\alpha-\mathrm{Fe}$ in equilibrium with the gas atmosphere, and $C_{N}^{s}$ is the actual $N$ surface concentration. Hence, the boundary condition at the surface can be derived by equating this flux of available $N$ on the surface with the flux of $N$ diffusing into the alloy given by Fick's first law, such that

$$
-\left.D \frac{i C_{N}}{i X}\right|_{X \|}=k\left(C_{N}-C_{N}\right)
$$

Rozendaal et al. ${ }^{17}$ employed the implicit C-N representation (Eq. (6)) to predict $N$ concentration profiles after various nitriding exposures. Good qualitative agreement was shown between predicted concentration profiles and microhardness profiles indicating a time dependence of the surface concentration $C *$. The predicted time dependence for various ammonia mixtures, and specifically the time to reach a critical surface concentration when $\gamma^{\prime} \mathrm{Fe}_{4} \mathrm{~N}$ would form, was used to explain the incubation time experimentally observed prior to $\gamma^{\prime} \mathrm{Fe}_{4} \mathrm{~N}$ formation.

\section{Oxidation and Oxygen Dissolution}

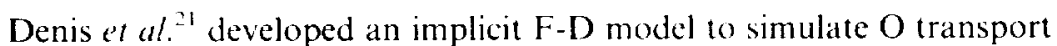
through an external scale and into the matrix. This model, revised from an earlier explicit model by Garcia ${ }^{26}$ in order to decrease computation times, presents a rare example of the use of a fixed-grid scheme with a moving boundary. Concentration-independent diffusion coefficients were assumed. The model was applied to the oxidation of Zircaloy-4 in water vapor which, as with many $\mathrm{Zr}$ alloys, initially obeys a parabolic law. However, continued oxidation results in a sharp transition to linear kinetics which are attributed 
to physical changes in the oxide $\left(\mathrm{ZrO}_{2},\right)$, such as pore and crack formation. The time interval each iteration, $\Delta t$, was chosen by an iterative process such that the new oxide metal interface position each iteration corresponded to a node location (i.e., a time increment was chosen such that the interface motion, $\Delta \Xi$, was always equal to the node spacing, $\Delta X$ ). In brief, this iteration process consisted of calculating new concentrations, $C_{0}^{i+1}$, using Eq. (6), and interface velocities, $d \xi d t$, using a flux balance equation similar to Eq. (12), for different values of $\Delta t$. An equation was derived relating the interface velocities and time increments which allowed an estimate of a new $\Delta t$ such that $\Delta \xi \approx \Delta X$. This process was repeated until a value of $\Delta t$ was achieved which produced an interface motion essentially equal to the node spacing.

For convenience, $O$ transport during the parabolic portion of the oxidation of Zircaloy was performed using analytical equations. Modeling the linear kinetics was accomplished in two ways. First, a time-dependent value for $D_{0}$, the diffusion coefficient in the zirconia scale, was used. To determine this time-dependence of $D_{0}$, the model was operated in a manner that a value for $D_{0}$ was determined each iteration such that the predicted sample weight gain, which was proportional to the predicted oxide thickness, matched that previously measured for the oxidation of Zircaloy. At a given temperature, the derived values for $D_{0}$, which were constant in the parabolic region, instantaneously increased at the transition from parabolic to linear kinetics, and increased linearly with time thereafter. Although timedependent diffusion coefficients have little physical significance, this example illustrates the flexibility of the F-D technique to handle time-dependent parameters.

The linear kinetics were also modeled by assuming a two-part oxide scale. 21 The model was revised to consider diffusional transport through an inner region of the $\mathrm{ZrO}_{2}$ scale only, while the outer region was assumed to offer no resistance to $\mathrm{O}$ transport due to formation and growth of pores and channels. The diffusion coefficient in the oxide was constant during both the parabolic and linear oxidation regimes. At the time of the parabolic/ linear transition, an interface was introduced in the oxide as the boundary between the porous layer containing channels and the dense inner layer which controlled diffusion. A schematic concentration profile indicating these layers is shown in Fig. 5. It was also assumed that the $O$ potential within the channels was the same as that of the environment such that the $O$ concentration throughout the porous oxide layer was assumed constant and equal to the concentration at the gas oxide interface, $C_{n}^{*}$. Since the weight of the sample increased linearly, and therefore the flux of $\mathrm{O}$ into the oxide was constant, the width of the dense inner oxide layer remained constant and moved into the Zircaloy at a constant rate. The usefulness of the 


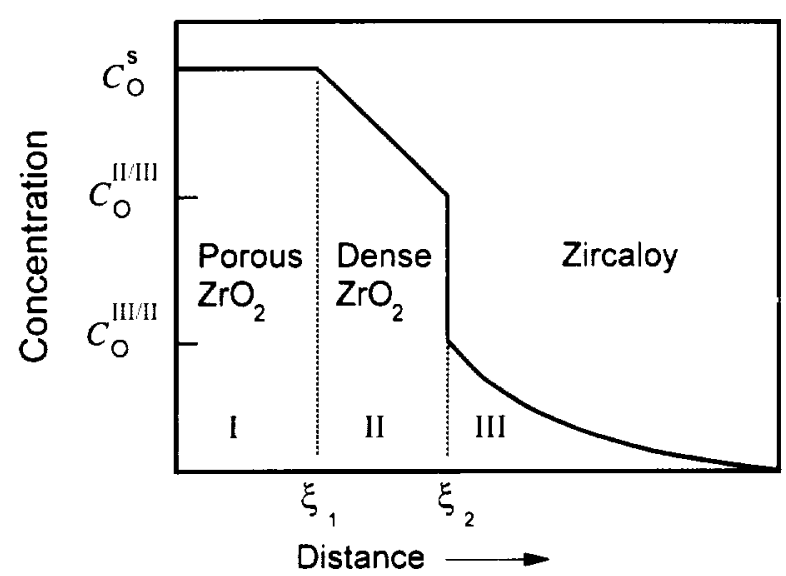

Fig. 5. Schematic $O$ concentration profile showing the twolayer $\mathrm{ZrO}_{2}$, scale on Zircaloy used by Denis et al. ${ }^{21}$

model was in determining the value for $D_{0}$ during the parabolic oxidation regime, and in developing a plausible model based on a dense inner oxide layer of constant thickness to explain the linear oxidation regime.

\section{Carburization}

Goldstein and Moren ${ }^{13}$ presented one of the earliest studies employing $\mathrm{F}-\mathrm{D}$ techniques to model $\mathrm{C}$ diffusion in $\mathrm{Fe} \mathrm{C}$ and $\mathrm{Fe} \mathrm{C} \mathrm{X}$ alloys, where $\mathrm{X}$ is a solute element such as $\mathrm{Ni}, \mathrm{Mn}, \mathrm{Cr}$ or $\mathrm{Si}$. Each of these elements is known to affect both the diffusivity and solubility of $\mathrm{C}$ in austenite. For the binary case, various carburization treatments were modeled where both the temperature and surface $C$ concentration, $C_{C}^{s}$, were time dependent. The temperature and concentration dependence of the diffusion coefficient of $\mathrm{C}$ in austenite, $D_{C}^{\gamma}$, were used in the model. However, since $D_{\mathrm{C}}^{\gamma}$ is not a strong function of concentration, the term $\partial D / \partial C(\partial C / \partial X)^{2}$ in Eq. (2c) was ignored so that concentration dependent values for $D_{C}^{\gamma}$ were used with Fick's second law given by Eq. (2b). A fixed-grid scheme was used with a constant number of nodes. Predicted and measured concentration profiles are shown in Fig. 6a. The variation of $C_{C}^{s}$ and temperature with time are shown in the inset. The agreement between the measured and predicted $C$ concentration is apparent.

For the ternary alloys, Goldstein and Moren ${ }^{13}$ gave the solute concentration $(\mathrm{Cr}$ or $\mathrm{Si})$ a steep concentration gradient near the surface, such as might occur due to limited oxidation prior to carburization, to evaluate the effect of the solute gradient on the diffusion of $\mathrm{C}$. In their work, the $\mathrm{C}$ content of the steel was fixed at $0.15 \mathrm{wt} . \%$ with a surface concentration of $1.0 \mathrm{wt} . \%$. The solute concentration, either $\mathrm{Cr}$ or Si, was set at $2 \mathrm{wt} . \%$ or 

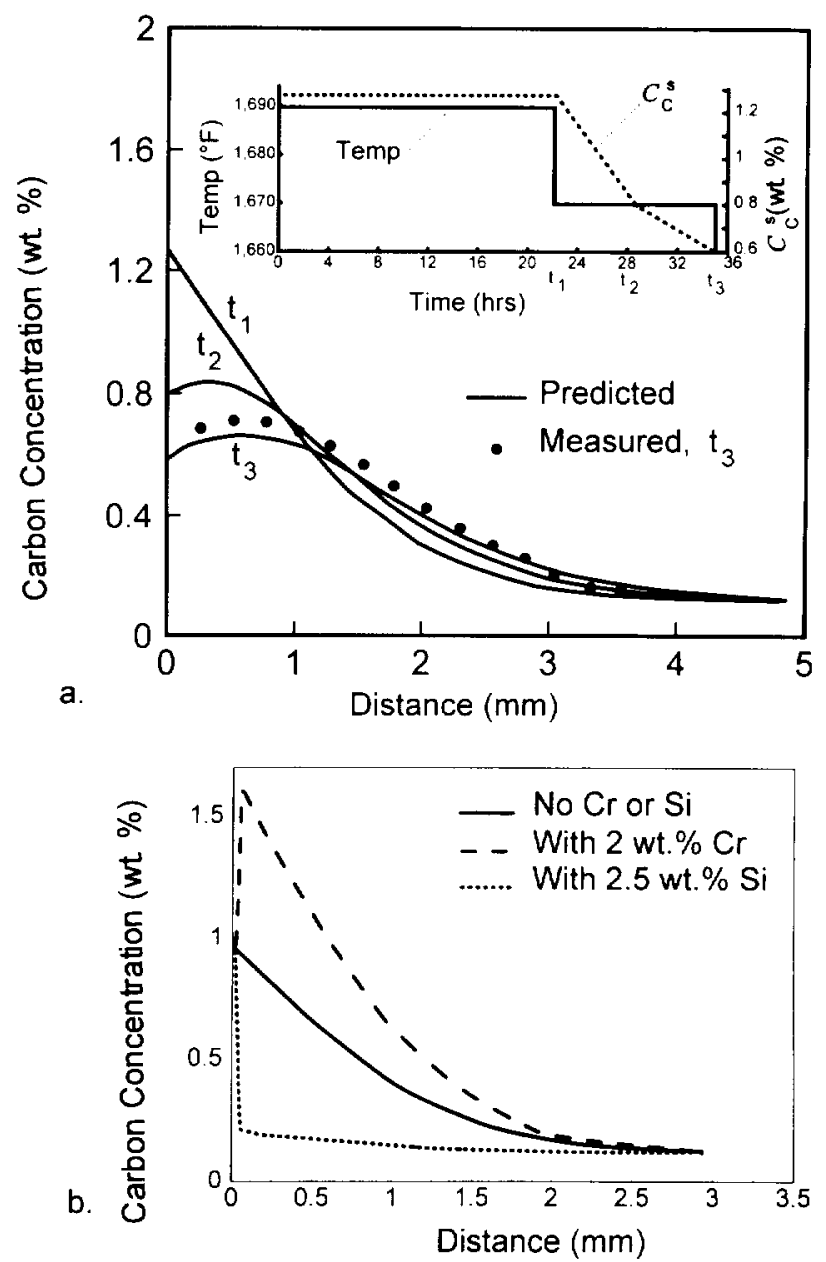

Fig. 6. (a) Predicted and measured $\mathrm{C}$ concentration profiles for the carburization treatment shown in the inset, and (b) predicted $\mathrm{C}$ concentration profiles for $\mathrm{Fe} 2 \mathrm{Cr} 0.15 \mathrm{C}, \mathrm{Fe} 2.5 \mathrm{Si} 0.15 \mathrm{C}$ and $\mathrm{Fe} 0.15 \mathrm{C}$ (wt. $\%$ ) alloys carburized at $1700 \mathrm{~F}$ for $8.31 \mathrm{~h}$. Surface $\mathrm{C}$ concentration $C_{C}^{4}=1.0 .^{13}$

$2.5 \mathrm{wt} . \%$, respectively, throughout the sample but zero at the surface node. Chromium, a strong carbide former, has a negative cross-term diffusion coefficient which is approximately one third the value of the main diffusion coefficient, or $D_{\mathrm{C}, \mathrm{C} \cdot \mathrm{C}} D_{\mathrm{C}, \mathrm{C}}=-0.34$ (i.e., a $\mathrm{Cr}$ concentration gradient opposite in sign to that of $C$ will increase the flux of $C$ [see Eq. (9)]). This relatively 
strong cross-term effect, coupled with a large, positive $\mathrm{Cr}$ concentration gradient near the surface, resulted in a maximum in the $\mathrm{C}$ concentration of nearly $1.7 \mathrm{wt} . \%$. The practical effect of this maximum is that more $\mathrm{C}$ diffusion occurs into this alloy than that for the binary alloy. In contrast, the crossterm effect in Si-containing alloys is positive (i.e., $D_{(\cdot \mathrm{s})} / D_{(\cdot, \cdot)}=+0.30$ ) such that the large positive Si concentration gradient near the surface caused a sharp decrease in the near-surface $\mathrm{C}$ concentration (i.e., the Si concentration gradient opposes the influx of $\mathrm{C}$ ). The predicted $\mathrm{C}$ concentration profiles for these three alloys. $\mathrm{Fe} \mathrm{C}, \mathrm{Fe} \mathrm{C} \mathrm{Cr}$ and $\mathrm{Fe} \mathrm{C}$ Si are shown in Fig. 6 b.

\section{Case II.B Corrodant Transport Accompanied by Internal Precipitation}

The inward transport of a corrodant often results in internal precipitation and subscale formation due to reaction of one or more alloying elements with the corrodant. The manner in which this precipitation is handled by F-D techniques depends, in large part, on the thermodynamic stability of the reaction product. Internal oxidation presents an example of the formation of a compound with high thermodynamic stability. Carbide formation during carburization presents an example of the formation of a compound with moderate thermodynamic stability.

Several of the following studies involving internal precipitation make use of a "labyrinth factor" to account for the reduction in cross-sectional area due to precipitate formation. This factor, which has a value between zero and one, is used to reduce the matrix diffusivity. The value of the labyrinth factor is generally related to the volume fraction of the remaining matrix.

\section{Internal Oxidation}

Internal oxidation involves the diffusion of $\mathrm{O}$ into an alloy and the formation of a subscale of solute oxide precipitates ( $\mathrm{BO}_{v}$ ). The high stability of many oxides results in an extremely low solubility product such that the concentration of solute in solution within the subscale and the $\mathrm{O}$ concentration at the subscale alloy interface (i.e., at the reaction front) is nearly zero. Furthermore, little $O$ penetrates beyond the precipitation zone into the alloy. Hence, for a highly stable oxide, it is generally assumed that (1) the oxide precipitation reaction occurs only at the subscale alloy interface (i.e., at $X=$ $\xi$ ); (2) all the solute in the subscale is converted to oxide (i.e., $C_{\mathrm{B}}=0$ within the subscale): and (3) the concentration of solute and $O$ at the subscalealloy interface is zero (i.e., $C_{\mathrm{B}}=C_{\mathrm{O}}=0$ at $X=\xi$ ). A grid is established for $O$ in the subscale and, if $B$ is sufficiently mobile. for $B$ in the alloy. (The diffusivity of alloying elements can be several orders of magnitude less than that for corrodants which diffuse interstitially (e.g., O, C and $\mathrm{N}$ ) such that 


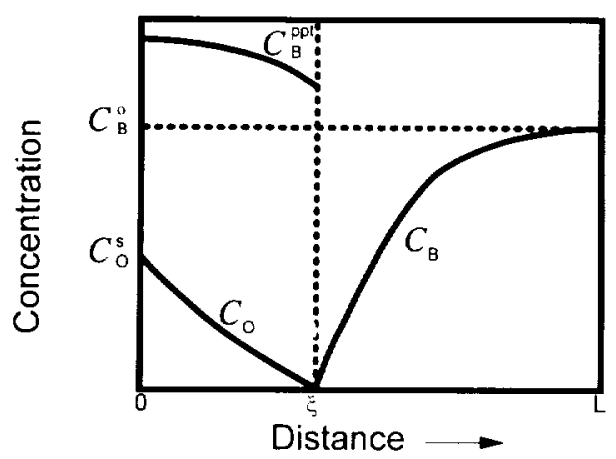

Fig. 7. Schematic concentration profiles for $\mathrm{O}(\mathrm{Co})$. solute $\mathrm{B}\left(C_{\mathrm{B}}\right)$, and $\mathrm{B}$ precipitated as $\mathrm{BO}_{v}\left(C_{\mathrm{B}} \mathrm{C}^{\mathrm{N}}\right)$ for the internal oxidation of a B-containing alloy where B forms a highly stable oxide $\mathrm{BO}_{1}$, ??

the alloying elements are often assumed to be immobile). Schematic concentration profiles for the outward diffusion of $\mathrm{B}$ and the inward diffusion of $\mathrm{O}$ are shown in Fig. 7. The flux of $\mathrm{O}$ and the flux of $\mathrm{B}$ arriving at the subscale alloy interface are related according to the stoichiometry of the precipitated oxide $\mathrm{BO}_{1}$, such that

$$
D_{\mathrm{B}} \begin{gathered}
\partial C_{\mathrm{B}} \\
\partial X
\end{gathered}\left|=-\begin{array}{cc}
D_{\mathrm{O}} & \hat{\partial} C_{\mathrm{O}} \\
v & \partial X
\end{array}\right|_{X=\xi}
$$

where $D_{0}$ is the diffusion coefficient of $\mathrm{O}$ in the alloy and $v$ is the stoichiometry factor. The interface motion $\Delta \xi$ in the time interval $\Delta t$ is given by a simple mass balance relationship which can be stated as

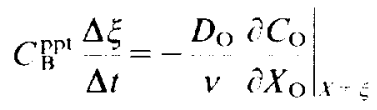

where $C_{3}^{p p 1}$ is the concentration of precipitated solute in the subscale (Fig. 7). The $O$ profile through the subscale is often assumed to be linear, which allows the $\mathrm{O}$ concentration derivative term $\partial C_{O}$ to be replaced with the $\mathrm{O}$ difference across the subscale (i.e., $C_{O}^{\mathrm{s}} 0$ ) and the distance derivative $i X$, to be replaced with the width of the subscale, $\xi$, yielding $C_{\mathrm{O}}^{\mathrm{s}} / \xi$ for the $\mathrm{O}$ concentration gradient in Eq. 16. If $\mathrm{B}$ is immobile, the concentration of $\mathrm{B}$ in the subscale $C_{\mathrm{B}}^{\mathrm{ppt}}$ (existing as $\mathrm{BO}_{1}$ ) remains equal to the concentration of $\mathrm{B}$ in the alloy $C_{\mathrm{B}}$. However, if reasonable diffusion of $\mathrm{B}$ does occur, $C_{\mathrm{B}}^{\mathrm{ppt}}$ in the subscale will exceed $C_{\mathrm{B}}$ in the alloy by an enrichment factor typically defined as $\alpha=C_{\mathrm{B}}^{\mathrm{pt}} / C_{\mathrm{B}}$. 
Vedula et al..$^{27}$ developed a F-D model to describe internal oxidation for planar, cylindrical and spherical geometries of finite size where the solute $B$ was considered mobile. The model was initially used to perform parametric analyses examining the subscale thickness and enrichment under isothermal conditions with a constant boundary condition ( $C_{O}^{\varsigma}$ constant), and was later extended to consider the effect of nonisothermal conditions and a timevarying boundary condition $\left(C_{O}^{\mathrm{s}}=f(t)\right)$. The concentration profiles in the alloy and subscale were determined by an explicit F-D method. Each iteration consisted of (1) calculating new concentrations at each node in the subscale and alloy according to Fick's second law, (2) calculating the interface motion $\Delta \xi$, (3) shifting the nodes in both the subscale and alloy and correcting the concentrations according to an M-L transformation, (4) calculating $C_{\mathrm{B}}^{\mathrm{ppt}}$ in the subscale (for $\alpha>1$ ).

The interface velocity $d \xi / d t$ is directly related to the $O$ flux into the alloy which is directly related to $C_{0}^{\mathrm{s}}$. It had previously been observed by Rapp $^{3}$ that the interface $\xi$ reversed directions when $C_{O}^{5}$ was quickly decreased. A second, more gradual interface reversal eventually occurs causing the interface to again move in the original direction into the alloy. This double interface reversal produces a localized band of high enrichment, known as an interruption band. This interface reversal was also quantitatively modeled by Vedula $e t$ al. ${ }^{27}$ for a sheet of thickness $L$. The normalized interface position, displaying an interface reversal of $\Delta \xi / L$, is shown in Fig. 8 (bottom). The rate of precipitate formation is directly related to the interface velocity. After the second reversal, the interface again moves into the alloy at a slower rate in accordance with the lower $O$ flux. The reduced interface velocity $(d \xi / d t)_{2}$ results in a higher rate of oxide precipitation, as shown in Fig. 8 (top). The second, more gradual interface reversal results in a "spike" in the rate of oxide precipitation.

\section{Carburization Accompanied by Carbide Formation}

The moderate stability of many carbides results in a much greater solubility product for the carbides in comparison to the oxides. Consequently, there can be significant $\mathrm{C}$ diffusion into the alloy beyond the carbide subscale and a significant concentration of the carbide-forming element within the subscale region. Since in many alloys of interest several carbides of the same element may form, it is useful to consider a carbide stability map such as that shown schematically in Fig. 9a for a simple binary alloy which forms carbides I. II and III (e.g., a Ni-Cr alloy with carbides $\mathrm{Cr}_{23} \mathrm{C}_{6}, \mathrm{Cr}_{7} \mathrm{C}_{3}$ and $\mathrm{Cr}_{3} \mathrm{C}_{2}$ ). Initially, consider a low $\mathrm{C}$ activity in the alloy, such as shown as point $\mathbf{P}$ in the figure. During carburization, $C$ will diffuse into the alloy raising the activity of $C$, as indicated by the dashed line $\mathbf{P Q}$. At point $\mathbf{Q}$, carbide $I$ begins to precipitate internally starting at the surface. Further 


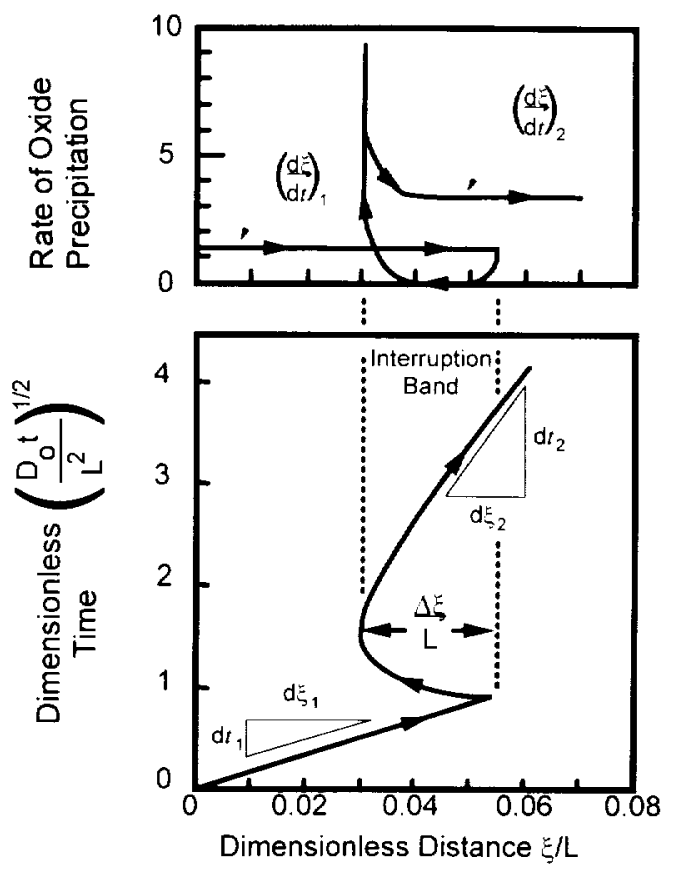

Fig. 8. Time versus distance plot showing a double interface reversal (bottom) and the associated rate of oxide precipitation (top) during internal oxidation. The interface velocities, where $(d \xi / d t)_{1}>(d \xi / d)_{2}$, are also shown. The arrows indicate the path direction. ${ }^{27}$

diffusion of $\mathrm{C}$ into the alloy will result in the inward growth of this carbide subscale layer while carbide I continues to form and grow within the layer itself (unlike that for internal oxidation where no further oxidation occurs in the subscale layer). If the $\mathrm{C}$ concentration at the outer surface remains constant, the subscale layer will thicken parabolically with time. As further carbide I formation occurs in the subscale, the activity and concentration of $\mathbf{B}$ in solution in the subscale decreases along the line indicated as $\mathbf{Q R}$ in Fig. 9a. When the $\mathrm{C}$ activity at the outer surface reaches that indicated by point $\mathbf{R}$, a carbide II layer will begin to form and grow inward as carbide I is converted to carbide II at the carbide I/II interface. Continued diffusion of $\mathrm{C}$ into the alloy will cause the continued growth of both carbide subscale layers along the lines QR (inner layer of carbide I) and along RS (outer layer of carbide II). If the $\mathrm{C}$ activity outside the alloy is sufficiently high, such as for $a_{\mathrm{C}}$ shown in Fig. 9a, a third carbide (III) may form at the outer surface and move inwardly with the C activity in subscale III following the line ST. 

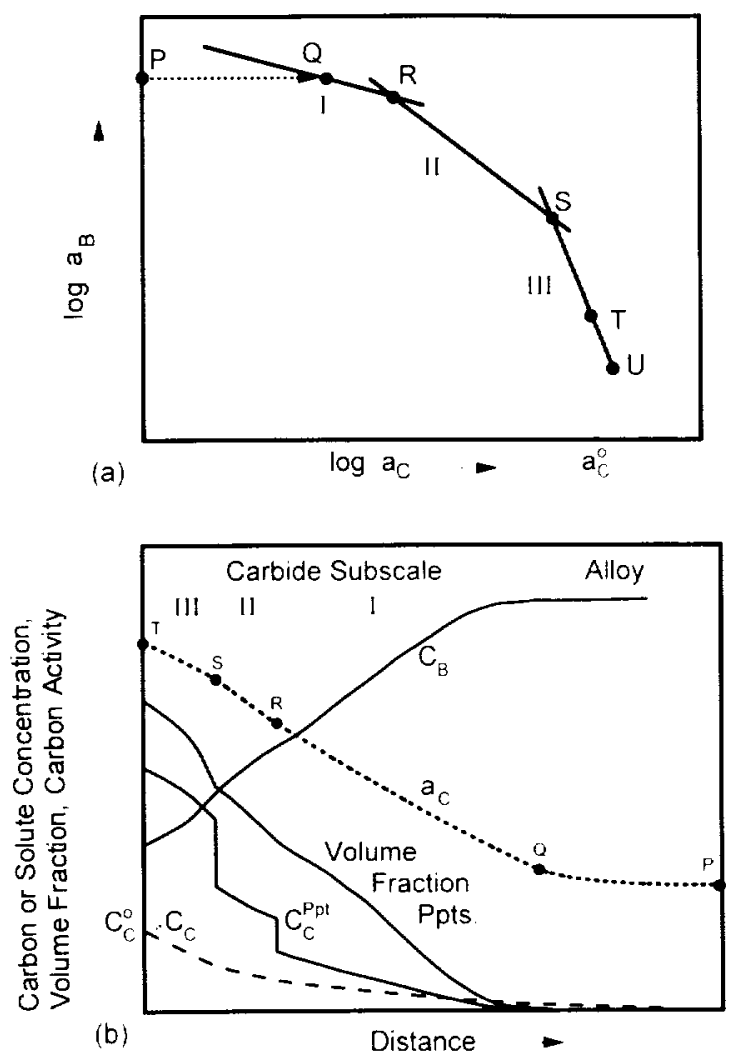

Fig. 9. Carburization of a binary alloy where three carbides may form with a single element $B$ (a) schematic carbide stability map and (b) schematic concentration profiles where subscales of three carbides in (a) are shown. (After Sockel et $\left(a l^{2 \times}\right)$

Schematic concentration profiles for the carburization of a binary alloy, based on the modeling predictions for $\mathrm{Ni}-25 \mathrm{Cr}$ by Sockel et al. ${ }^{28}$ are shown in Fig. 9b. The solute B was assumed immobile. There is a significant concentration of the solute $\mathrm{B}$ within the subscale and a small but apparent amount of $C$ in the alloy below the carbide I subscale resulting from the moderate stability of the carbides. The $\mathrm{C}$ activity, indicating the activities of interest from Fig. 9a (P, $\mathbf{Q}, \mathbf{R}, \mathbf{S}, \mathbf{T})$, is also shown schematically in Fig. $9 b$.

Two methods appear in the literature to model, by F-D techniques, the carburization process when accompanied by carbide formation. Both methods handle formation of multiple carbides of the solute $\mathrm{B}$. The first 
and earlier method, used by Bongartz et al..$^{18}$ uses a two-step procedure at each node to calculate the concentration of $B$ and $C$ in solution and in the carbide for the current time iteration $\Delta t$. The two steps involve, firstly, a diffusion calculation, and secondly, an equilibrium calculation to partition the solute and $C$ between that which remains in solution and that which forms the carbide. The first step calculates the $\mathrm{C}$ diffusion to a node in the time interval $\Delta t$ according to Fick's second law. Typically, this step increases the $\mathrm{C}$ concentration of the node. The second step compares the product of the current $\mathrm{C}$ and $\mathrm{B}$ concentrations with the solubility product for the carbide, $K_{1}$. The excess $\mathrm{C}, \Delta \mathrm{C}$, above that given by $K_{1}$, is assumed to form carbide. The concentration of soluble $\mathrm{C}$ at the node is reduced by $\Delta \mathrm{C}$ while the concentration of $\mathrm{C}$ in the carbide is increased by $\Delta \mathrm{C}$. The quantity of $B$ which is involved in the carbide formation with $\Delta C$ is also removed from the concentration of soluble $B$ at the node. The new $C$ concentration of the node, which now satisfies $K_{s}$, is assumed available to diffuse to the next node where this two-step process is repeated. The activities associated with these concentrations of $\mathrm{C}$ and $\mathrm{B}$ at this particular node will correspond to a point on the line $\mathbf{Q R}$ on the carbide stability map shown in Fig. 9a. This two-step procedure begins at the outer nodes and progresses inward. As time progresses and the concentration of $\mathbf{B}$ in solution decreases while the concentration of $\mathrm{C}$ increases, the activities will follow the line from $\mathbf{Q}$ to $\mathbf{R}$. When point $\mathbf{R}$ is reached, carbide II will also be stable at this node. Further diffusion of $\mathrm{C}$ to this node will only result in the transformation of carbide I to carbide II without a further change in the concentrations of $\mathrm{B}$ or $\mathrm{C}$ until all of carbide $I$ at the node has been transformed. Thereafter, further diffusion of $\mathrm{C}$ to this node will cause additional formation of carbide II while the concentrations, and activities of $\mathrm{B}$ and $\mathrm{C}$ in solution at the node now follow along the line RS in Fig. 9 a

This two-step procedure was extended to the problem where many carbides of different solute elements may exist simultaneously, as for the case of the carburization of various $\mathrm{Fe} \mathrm{Ni} \mathrm{Co} \mathrm{Cr}$ Mo alloys. ${ }^{29}$ For the second step in this case, the excess $\mathrm{C}, \Delta \mathrm{C}$, which exceeds the solubility limit of the various possible carbides must be partitioned between those carbides. For $M$ possible carbides, the excess $C$ can be described as $\Delta C=\sum \Delta C_{M}$ where $\Delta \mathrm{C}_{\mathrm{M}}$ reflects the $\mathrm{C}$ tied up in each of the various carbides which can contain varying amounts of $M$, where $M$ stands for the carbide-forming element (e.g., Cr, W, Ti). By assuming a regular solution model for the matrix, a series of $\mathrm{M}$ nonlinear equations, based on concentrations known at time $t_{1}$, can be derived to determine the $M$ values of $\Delta C_{M}$. Numerical methods were used to solve for each of the $\Delta C_{M}$ 's. This procedure is used repetitively at each node to determine the $\mathrm{C}$ in solution and that in each of the carbides as a function of position in the sample. 


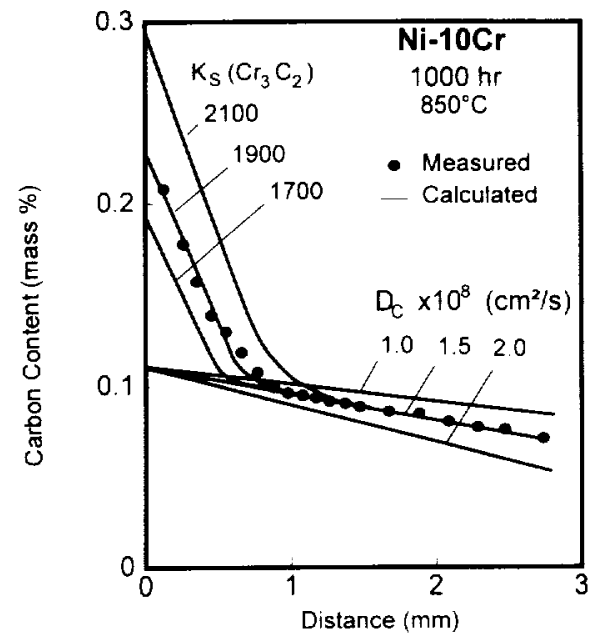

Fig. 10. Measured and predicted $C$ concentration profiles following carburization of a $\mathrm{Ni} 10 \mathrm{Cr}$ alloy. The various predicted curves represent the indicated values for the solubility product $K$, for $\mathrm{Cr}_{3} \mathrm{C}_{2}$ and $D_{\mathrm{C}}{ }^{30}$

Bongartz et al. ${ }^{30}$ applied these models to the carburization of various $\mathrm{Ni}-\mathrm{Cr}$ alloys. Although the necessary thermodynamic and kinetic data (primarily the solubility products for each carbide, activity coefficients, $\gamma_{C}$, $\gamma_{\mathrm{Cr}}$, and $D_{\mathrm{C}(\mathrm{c})}$ exist in the literature, these published data exhibit significant scatter. It was shown that the calculated $\mathrm{C}$ profiles are very sensitive to the thermodynamic and kinetic data, as shown for a $\mathrm{Ni} 10 \mathrm{Cr}$ alloy in Fig. 10. Hence, Bongartz et al. matched predicted and measured $\mathrm{C}$ profiles to get the most reasonable value for $D_{C, C}$ and the solubility products for the $\mathrm{Ni}$ $10 \mathrm{Cr}$ alloy. The values for $D_{\mathrm{C}, \mathrm{C}}, \gamma_{\mathrm{C}}$ and the solubility product for $\mathrm{Cr}_{3} \mathrm{C}_{2}$ determined from the $\mathrm{Ni} 10 \mathrm{Cr}$ alloys were then applied to gain the solubility products for $\mathrm{Cr}_{7} \mathrm{C}_{3}$ and $\mathrm{Cr}_{23} \mathrm{C}_{6}$. Because of the sensitivity of the calculated profiles to the input data, the authors clearly demonstrated the usefulness of the F-D technique, when combined with reliable experimental concentration measurements, to derive important thermodynamic and kinetic data.

Bongartz et $a l^{18}$ also simulated carburization and carbide precipitation in Fe-based alloys with planar, cylindrical or spherical geometries. A constant $C$ flux, determined as an average value from the $C$ pickup on experimental samples, was taken as the outer surface boundary condition. Similar to the systematic approach stated above, predicted and measured $\mathrm{C}$ concentration profiles in $\mathrm{Fe} \mathrm{Ni} \mathrm{Cr}$ alloys were used to derive an approximate 
diffusion coefficient for $\mathrm{C}$ in this alloy. Likewise, the solubility product for $\mathrm{NbC}$ was then derived by comparing measured and predicted total $\mathrm{C}$ concentration profiles ( $\mathrm{C}$ in solution and as carbides) in $\mathrm{Fe}-\mathrm{Ni}-\mathrm{Cr}-\mathrm{Nb}$ alloys. The model was then used to make semiquantitative predictions of the degradation of $\mathrm{Fe} \mathrm{Ni} \mathrm{Cr} \mathrm{Nb}$ tubes exposed to a carburizing environment at $900^{\circ} \mathrm{C}$ for times up to $100,000 \mathrm{~h}$ (i.e., 15-year operation in a petrochemical plant or in the steam reformer of a nuclear process heat system). The predictions were able to quantify the difference in carburization attack for the condition of a constant $\mathrm{C}$ concentration at the outer surface (i.e., a high and unlimited supply of $\mathrm{C}$ from the environment controlled only by diffusion into the alloy) versus a constant flux of $\mathrm{C}$ at the outer surface (i.e., the more common situation where the rate of supply of $\mathrm{C}$ to the alloy is limited by the decomposition of the carburizing species (e.g., methane) at the alloy surface or gasoxide interface if an oxide scale is present).

Bongartz et al $^{29}$ later utilized the same systematic approach to model the carburization of various binary, ternary and quaternary $\mathrm{Ni}-\mathrm{Fe}-\mathrm{Cr}$ and $\mathrm{Ni}-\mathrm{Co}-\mathrm{Cr}-\mathrm{Mo}$ alloys. Data, where available, were taken from the literature. However, values for $\gamma_{C}$ and $D_{C, C}$ were determined by fitting measured and predicted $\mathrm{C}$ profiles in binary alloys which were carburized in an atmosphere which did not form carbides. Thermodynamic data for the more complex carbides were determined by systematically fitting measured and predicted $\mathrm{C}$ profiles in the progressively more complex alloys. The wide range of solubility of some carbides (i.e., $\mathrm{Cr}_{23} \mathrm{C}_{6}$ and $\mathrm{Cr}_{7} \mathrm{C}_{3}$, can dissolve significant amounts of $\mathrm{Fe}, \mathrm{Ni}$ and $\mathrm{Mo}$ ) was approximated by several carbides with selected discrete stoichiometries. For example, in $\mathrm{Ni} \cdot \mathrm{Fe} \mathrm{Cr}$ alloys, the $\mathrm{Cr} / \mathrm{Fe}$ ratio changes continuously in the $\mathrm{M}_{7} \mathrm{C}_{3}$ carbide. This carbide was therefore approximated by the two carbides of fixed stoichiometry, $\mathrm{Cr}_{4} \mathrm{Fe}_{3} \mathrm{C}_{3}$ and $\mathrm{Cr}_{5} \mathrm{Fe}_{2} \mathrm{C}_{3}$. The equilibrium constants were determined by assuming the mixed $\mathrm{Fe} \mathrm{Cr}$ carbides to be regular solutions of the stable phase $\mathrm{Cr}_{7} \mathrm{C}_{3}$. The model gave very good agreement with the predicted $\mathrm{C}$ concentration profiles for the binary $\mathrm{Ni}$. $\mathrm{Cr}$ alloys and also agreed well with the new experimental ręsults for the carbide distributions. In the ternary and quaternary alloys, reasonable agreement was also found considering the simplifying assumption of approximating the continuously varying carbide compositions with discrete stoichiometric carbides.

Farkas and Ohla ${ }^{14}$ followed the two-step approach of Bongartz et al. ${ }^{18}$ in modeling the simultaneous precipitation of up to three carbides but included the ternary cross-term effect of a substitutional element. A nearsurface region was depleted of $\mathrm{Cr}$ in three commercial superalloys and two $\mathrm{Fe}-\mathrm{Ni} \mathrm{Cr}$ alloys by preoxidizing at $900 \mathrm{C}$ for $100 \mathrm{~h}$. Similar to the studies of Bongartz, measured and predicted $\mathrm{C}$ profiles were used to derive approximate values for $D_{C, C}$ in the alloys. The derived values for $D_{\mathrm{C}, \mathrm{C}}$ were in 


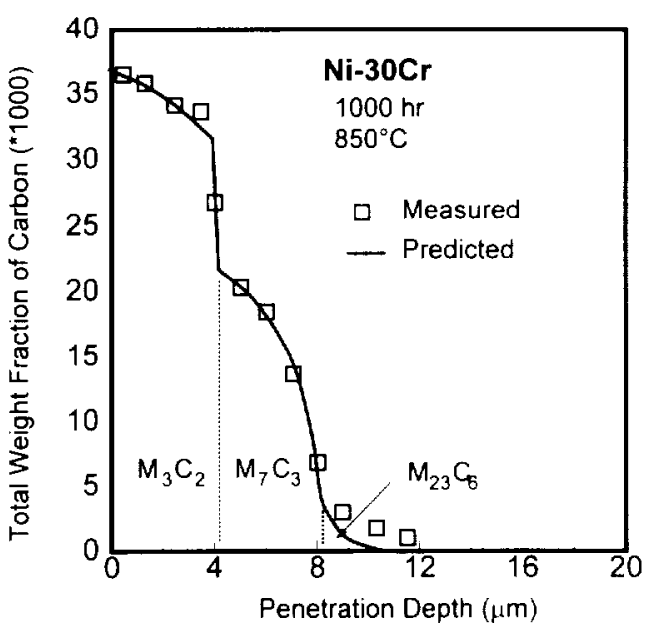

Fig. 11. Measured and predicted $\mathrm{C}$ concentration profiles for the carburization of a $\mathrm{Ni} 30 \mathrm{Cr}$ alloy. (After Engström eq $a l^{3 ?}$ )

reasonable agreement with values determined in other studies. The measured and predicted $C$ profiles showed the need to account for the ternary crossterm effect when predicting carburization in multicomponent alloys. Farkas et al. ${ }^{31}$ later applied a similar model to the carburization and sulfidation of $\mathrm{Ni} \mathrm{Cr}$ Mo alloys. As expected, for the same time and temperature conditions, $\mathrm{S}$ penetration and sulfide precipitation are significantly less than that associated with carburization since $S$ diffuses as a substitutional element in contrast to the interstitial diffusion of $\mathrm{C}$.

Engström et al. ${ }^{32}$ also followed the two-step approach of Bongartz but developed a generalized numerical model which makes use of a thermodynamic package to make all equilibrium calculations. There are no restrictions on the number of components or phases which occur in the problem to be modeled as long as thermodynamic and kinetic data are available. The model also utilizes a labyrinth factor equal to the square of the volume fraction of remaining matrix. This model, which incorporates no adjustable parameters, was also applied to the carburization of $\mathrm{Ni} \mathrm{Cr}$ alloys and evaluated with previously published experimental data. ${ }^{29,31}$ Because of the direct link with the thermodynamic program, the model was able to account for the variable composition of the carbides which were modeled discretely by Bongartz. ${ }^{29}$ All other data used by the model were determined independently. There was reasonable agreement between the calculated $C$ profiles and carbide distributions, as shown in Fig. 11. Although only data measured 
independently were used in the calculations, the values used (e.g., $D_{\text {c.c. }}$ ) were not reported to allow a comparison to the values determined in the progressive manner by Bongartz. ${ }^{29}$

The second method to model the carburization process when accompanied by carbide precipitation was presented by Sockel $e t a l^{2 x}$ In this approach, the precipitation reaction is included in Fick's second law. Following the treatment by Sockel, the total $\mathrm{C}$ concentration is given as $C_{C}^{\mathrm{tot}}=C_{\mathrm{Cp}}^{\mathrm{pp}}+C_{\mathrm{C}}$, where $C_{C}^{\mathrm{ppt}}$ is the precipitated $\mathrm{C}$ in the carbide and $C_{\mathrm{C}}$ is the $\mathrm{C}$ in solution. The concentration term in Fick's second law, $C \mathrm{C} / \mathrm{C} t \mathrm{(Eq}$. (2a)), must be modified to include the total $C$ concentration, $C_{C}^{\text {tot }}$, which will change with time. However, other terms in Fick's second law remain unchanged since the precipitated $\mathrm{C}$ does not contribute to the $\mathrm{C}$ flux. By assuming ideal solution behavior, the solubility product for $a B_{b} C_{a t}$ carbide is given as $K_{s}=C_{\mathrm{B}}^{\mathrm{b}} C_{\mathrm{C}}^{\mathrm{i}}$, the concentration of precipitated $\mathrm{C}$ becomes

$$
C^{\mathrm{ppt}}=\frac{a}{b}\left(C_{\mathrm{B}}^{\mathrm{tot}}-\frac{K^{1} \cdot b}{C_{\mathrm{C}}^{a} \cdot \vec{b}}\right)
$$

where $C_{B}^{(x)}$ is the total concentration of $B$ at a particular location in the carbide subscale layer, defined as $C_{B}{ }^{p t}+C_{B}$. Inserting these equations into Fick's second law, and assuming that $D_{C, C}$ is independent of concentration, yields

$$
\left\{1+\left(\frac{a}{b}\right)^{2}\left(\frac{K_{s}}{C_{c}^{a+h}}\right)^{1, h}\right\} \frac{\partial C_{C}}{\partial t}=D_{C} \frac{\partial^{2} C_{C}}{\partial X^{2}}
$$

F-D equivalents can again be substituted for the derivatives in this equation. however, the equation is now nonlinear and the concentration of $C$ in solution, $C_{C}$, at the new time $t+\Delta t$ cannot be solved for directly but requires an iterative numerical technique. ${ }^{9}$ Sockel $^{28}$ utilized these equations for the case where the solute $B$ was immobile which yields a constant value for $C_{\mathrm{B}}^{\mathrm{tox}}$ in Eq. (17). Hence, when $C_{\mathrm{C}}$ was determined in Eq. (18), the value for $C_{C}^{\text {npt }}$ could be calculated using Eq. (17) and $C_{B 3}$ and the totals, $C_{C}^{\text {tot }}$ and $C_{B}^{\text {tot }}$ could be easily determined. If $B$ is mobile, two equations similar to Eqs. (17) and (18) could be derived also for B. However, for each node within the carbide subscale zone, the F-D equivalents to Eq. (18) for both $\mathrm{B}$ and $C$ would have to be each iteratively solved to obtain values for $C_{\mathrm{B}}$ and $C_{C}$. which also satisfied the solubility product, a significant amount of calculation for the concentrations at each node!

Sockel et al. ${ }^{28}$ utilized the approach outlined above to model the carburization of $\mathrm{Ni}$ 25Cr alloys under conditions where $\mathrm{Cr}_{3} \mathrm{C}_{2}, \mathrm{Cr}_{7} \mathrm{C}_{3}$ and $\mathrm{Cr}_{23} \mathrm{C}_{6}$ form. A labyrinth factor, approximately equal to the volume fraction of the remaining matrix, was used. Sockel assumed a constant value for $D_{C}$, an 
ideal solution model, and an immobile $\mathrm{Cr}$ solute. Data were taken from the literature for $D_{\mathrm{C}}$ and $K_{s}$ for each of these carbides, these latter values which had to be "corrected" in order to be used in the computer calculations. Good agreement was obtained between the measured and predicted weight gain during carburization of $\mathrm{Ni}-25 \mathrm{Cr}$ alloys. There was also reasonable agreement between the measured and predicted volume fraction of carbides versus distance in these alloys. As expected, the predictions also show that the thickness of each of the carbide layers increases parabolically with time.

\section{FUTURE}

The intent of the preceding discussion was to demonstrate that F-D techniques have the flexibility to simulate the diffusional transport associated with most high-temperature corrosion problems of interest. The tremendous advances in computing power have taken the solution of these problems from the exclusive domain of mainframe computers to the common task of desktop PCs in less than 10 years. However, as at the time of the earliest studies using numerical methods to model diffusional transport, the chief impediment in performing numerical modeling of diffusion processes lies in the lack of accurate thermodynamic (e.g., phase stabilities and solubilities) and kinetic data (e.g., diffusion coefficients). Most of the studies discussed above cite this as an obstacle to more detailed analyses. Unfortunately, one of the limitations of the F-D technique is that it cannot be "inverted" to directly yield concentration-dependent diffusivity data, although several of the studies discussed above used the technique to "back-calculate" apparent diffusivities (see Refs. 18, 29, 30).

Two statements can be made here for future directions. First, is the need for more work in line with the approach taken by Engström ${ }^{32}$ in linking predictive thermodynamic packages with diffusion models. With sufficient data, these thermodynamic programs can predict the phase relationships and boundaries for multiphase and multicomponent alloys critical to the application of the diffusion models. However, a dearth of diffusivity data, especially in multicomponent alloys, continues. This lack of data is not likely to be quickly remedied considering the extensive amount of concentration data required to measure $D \mathrm{~s}$ in ternary and higher order systems. Morral, Thompson and co-workers, ${ }^{33.34}$ have developed a different approach of predicting diffusion in multicomponent, multiphase alloys. This approach utilizes a "square-root diffusivity" matrix $[r]$ to predict interdiffusion. Although the analysis assumes concentration independence, the elements of the $[r]$ matrix can be determined with less experimental work than the traditional Boltzmann Matano analysis to yield $[D]$. In any multicomponent system, 
the $[r]$ matrix is related to the familiar diffusivities by $[D]=[r][r]$. The accuracy and usefulness of the approach for multicomponent alloys has been demonstrated in predicting concentration profiles in $\mathrm{Ni}-\mathrm{Cr}-\mathrm{Al}-\mathrm{Mo}$ alloys. ${ }^{35}$ The approach has also been applied to predict coating-substrate interdiffusion in multicomponent systems ${ }^{36}$ and to investigate the effect of third element additions in helping to establish an external, protective, solute scale. ${ }^{37}$ Incorporating the square root diffusivity analysis into the F-D technique may allow modeling diffusional transport associated with high-temperature corrosion in more complex commercial alloys. Certainly the necessary kinetic data, nearly impossible to measure using traditional approaches, will be easier to measure with this approach. ${ }^{38}$

Lastly, most diffusion analyses are performed on relatively simple geometries, planar, cylindrical or spherical. In applications where the shape cannot be reduced to these simple geometries, more complex, commercial, heat transfer codes may be used. In this case, the temperature-dependent thermal diffusivity is replaced by a concentration-dependent kinetic diffusivity. These codes, such as SINDA ${ }^{39}$ (Systems Improved Numerical Differencing Analyzer), typically have considerable flexibility in handling timedependent boundary conditions, complex starting conditions, and moving boundaries. The drawback to these codes is that they are often extensive programs containing numerous capabilities and are generally resident on mainframe computers.

\section{ACKNOWLEDGMENTS}

The author would like to acknowledge Michael Brady, National Research Council Postdoctoral Fellow at the NASA Lewis Research Center, for many helpful comments and suggestions regarding this manuscript.

\section{REFERENCES}

1. C. Wagner, J. Electrochem. Soc: 99, 369 (1952).

2. S. W. Guan, H. C. Yi, and W. W. Smeltzer, Oxid. Met. 41,389 (Pt. I), 401 (Pt. II) (1994).

3. R. A. Rapp, Acta Metall. 9, 730 (1961).

4. R. F. Sekerka, C. L. Jeanfils, and R. W. Heckel, in Lectures on the Theory of Phase Transformations, H. I. Aaronson (ed.) (TMS-AIME, New York, 1975), p. 117.

5. J. A. Nesbitt, J. Electrochem. Soc. 136, 1511 (1989).

6. J. Crank, The Mathematics of Diffusion (Clarendon Press, Oxford, 1975).

7. W. Jost, Diffusion in Solids. Liquids, Gases (Academic Press, New York, 1952).

8. J. Ågren, J. Phys. Chem. Solids 43, 385 (1982).

9. R. W. Hornbeck, Numerical Methods (Quantum Publishers, New York, 1975).

10. M. L. James, G. M. Smith, and J. C. Wolford, Analog and Digital Computer Methods (International Textbook. Scranton, 1964).

11. J. A. Nesbitt and R. W. Heckel, Thin Solid Films 119, 281 (1984)

12. E. Y. Lee, D. M. Chartier. R. R. Biederman. and R. D. Sisson, Jr., Surf. Coat. Technol. 32, 19 (1987). 
13. J. I. Goldstein and A. E. Moren, Met. Trans. 9A, 1515 (1975).

14. D. Farkas and K. Ohla, Oxid. Met. 19. 99 (1983).

15. J. A. Nesbitt. J. Electrochem. Soc. 136, 1518 (1989).

16. J. A. Nesbitt and E. J. Vinarcik, in Damage and Oxidation Protectom in High Temperature Composites, G. K. Haritos, and O. O. Ochoa, eds.. AD-Vol 25-I (ASME, 1991), p. 9.

17. H. C. F. Rozendaal. E. J. Mittemeijer. P. F. Colign, and P. J. Van Der Schaaf, Met. Trans. 14A. 395 (1983).

18. K. Bongartz, D. F. Lupton, and H. Schuster, Met. Trans. 11A. $1883(1980)$

19. D. Murray and F. Landis, J. Heat Trunsfer 81, 106 (1959).

20. S. Crusius, G. Inden, U. Knoop, L. Höglund, and J. Agren, Z. Metallkd. 83. 673 (1992)

21. A. Denis, E. Moyano, and A. Garcia, J. Nucl. Mater. 110, 11 (1982).

22. D. P. Whittle. D. J. Evans, D. B. Scully, and G. C. Wood. Acta Metall. 15, $1421(1967)$

23. D. P. Whittle, G. C. Wood, D. J. Evans, and D. B. Scully, Actu Metall. 15, 1747 (1967)

24. C. E. Lowell, C. A. Barrett, R. W. Palmer, J. V. Auping. and H. B. Probst, Oxid. Mer 36. $81(1991)$.

25. J. A. Nesbitt, in Diffusion Analysis and Applications, A. D. Romig, Jr, and M. A. Dayananda (eds) (TMS, Allendale. 1989), p. 307

26. E. A. García, J. Nuct Mater. 92,249 (1980).

27. K. M. Vedula, A. W. Funkenbusch, and R. W. Heckel. Oxid. Met. 16, 385 (1981)

28. H. G. Sockel, H. J. Christ, and W. Christl. Mater, Sci. Eng. 87. 119 (1987).

29. K. Bongartz. W. J. Quadakkers, R. Schulten, and H. Nickel. Mot. Trans. 20A, 1021 (1989),

30. K. Bongartz, R. Schulten, W. J. Quadakkers, and H. Nickel. Corrosion 42, 390 (1986).

31. D. Farkas. H. Ghasemi, and K. Grantz, in High Temperature Allow: Theory and Design (TMS-AIME. Warrendale. 1984), p. 125

32. A. Engström, L. Höglund, and J. Ågren, Met. Mater. Trants. 25A. 1127 (1994).

33. M. S. Thompson and J. E. Morral. Acra Metall. 34, 339 (1986)

34. M. S. Thompson and J. E. Morral, Acta Metall. 34, 2201 (1986).

35. M. K. Stalker, J. E. Morral and A. D. Romig. Jr.. Met. Trans. 23A. 3245 (1992)

36. M. S. Thompson and J. E. Morral, in High Temperature Conings. M. Khobaib and R. C Krutenat (eds) (TMS-AIME, Warrendale, 1987), p. 55

37. J. E. Morral, M. S. Thompson, and O. F. Devereux. Scripta Matall 20. 1355 (1986).

38. J. E. Morral, Y.-H. Son, and M. S. Thompson, in Fiendamentals and Applications of Ternary. Diffusion. G. R. Purdy (ed.) (Pergamon Press, Elmsford, 1990) p. 119

39. SINDA/FLLINT, available through COSMIC. The University of Georgia, Athens. GA 